\title{
Sistem Informasi Geografis Sebagai Alat Monitoring Terhadap Apotek Kerja Sama PT Bayer Indonesia
}

\author{
Reksi Arismunandar* \\ Program Studi Teknik Informatika, Politeknik Negeri Jakarta \\ (corresponding author) reksi.arismunandar.tik13@mhsw.pnj.ac.id*
}

\begin{abstract}
Apotek kerja sama (APKS) is one of channel in cooperation with PT Bayer Indonesia for marketing the products who produced by the pharmaceuticals business in Indonesia. The large number of APKS spread across several regions in Indonesia, making the business channel department as the department responsible for APKS feels it difficult to monitor and make decisions in terms of distributing and selling products to APKS. The best solution that can be done to solve the problem is to build a geographic information system that can map APKS in accordance with geographical area. With geographic information system, business channel department can have materials to analyze the needs of the products to be distributed and sold to each pharmacy cooperation in various regions and can determine the ideal number of cooperative pharmacies in each region. In the APKS Information System development process, the method used is the FAST (Framework for the Application of Systems Techniques) method. FAST method is chosen as APKS Information System development method because this method uses many approaches in system analysis which is popular approach, so that expected analysis result will be more sharp and accurate.
\end{abstract}

Keyword- APKS, geographic information system, sales, monitoring, FAST methods.

Intisari- Apotek kerja sama (APKS) merupakan salah satu channel yang bekerja sama dengan PT Bayer Indonesia untuk memasarkan produk-produk yang di produksi oleh bisnis pharmaceuticals di Indonesia. Jumlah APKS yang cukup banyak dan tersebar di beberapa wilayah di Indonesia, membuat departemen business channel sebagai departmen yang bertanggung jawab terhadap APKS merasa kesulitan untuk memantau dan mengambil keputusan dalam hal pendistribusian dan penjualan produk-produk kepada APKS. Solusi terbaik yang dapat dilakukan untuk menangani permasalahan tersebut adalah dengan adanya suatu sistem informasi geografis yang dapat memetakan APKS sesuai dengan wilayah geografisnya. Dengan adanya sistem informasi geografis maka departemen business channel dapat memiliki bahan untuk menganalisis kebutuhan produk untuk didistribusikan dan dijual ke setiap apotek kerja sama di berbagai daerah serta dapat menentukan jumlah ideal apotek kerja sama di setiap daerah. Dalam proses pengembangan Sistem Informasi APKS, metode yang digunakan adalah metode FAST (Framework for the Application of Systems Techniques). Pemilihan metode FAST sebagai metode pengembangan Sistem Informasi APKS karena metode ini menggunakan banyak pendekatan dalam analisis sistem yang merupakan pendekatan populer, sehingga hasil analisis yang diharapkan akan lebih tajam dan akurat.

Kata Kunci-APKS, sistem informasi geografis, penjualan, monitoring, metode FAST.

\section{Pendahuluan}

PT Bayer Indonesia adalah perusahaan dengan kompetensi di bidang life science terkait kesehatan dan pertanian. Sebagian besar produk yang di produksi oleh PT Bayer Indonesia diekspor ke negara-negara di seluruh dunia serta dipasarkan di wilayah Indonesia [1].

Untuk memasarkan produk-produk tersebut di Indonesia, PT Bayer Indonesia bekerja sama dengan berbagai pihak seperti, rumah sakit, klinik, dan apotek. Salah satu pihak yang memiliki kontribusi cukup besar untuk menjual produkproduk dari PT Bayer Indonesia adalah apotek. Apotek memiliki peran sebagai perantara bagi PT Bayer Indonesia untuk menjual produk-produk yang produksi oleh bisnis pharmaceuticals kepada konsumen. Sebagian besar produk yang di distribusikan kepada apotek adalah produk-produk yang berhubungan dengan kesehatan wanita [2] dan obat-obatan dengan resep [3].

Untuk memberikan perlakuan khusus kepada apotek-apotek tersebut, departemen business channel dari bisnis pharmaceuticals PT Bayer Indonesia membuat pengkategorian terhadap apotek-apotek yang dinilai mampu memberikan kontribusi terhadap penjualan beberapa produk yang di produksi oleh bisnis pharmaceuticals yaitu dengan membuat apotek kerja sama (APKS). Dengan adanya APKS ini, maka apotek-apotek yang terdaftar sebagai APKS di PT Bayer Indonesia akan mendapatkan perlakuan khusus seperti diskon setiap pembelian beberapa produk yang di produksi oleh bisnis pharmaceuticals. 
Berikut merupakan data dalam bentuk diagram yang didapat dari departemen business channel, dimana diagram tersebut menggambarkan perbandingan kontribusi APKS terhadap channel lain dalam penjualan beberapa produk dari bisnis pharmaceuticals pada tahun 2016:

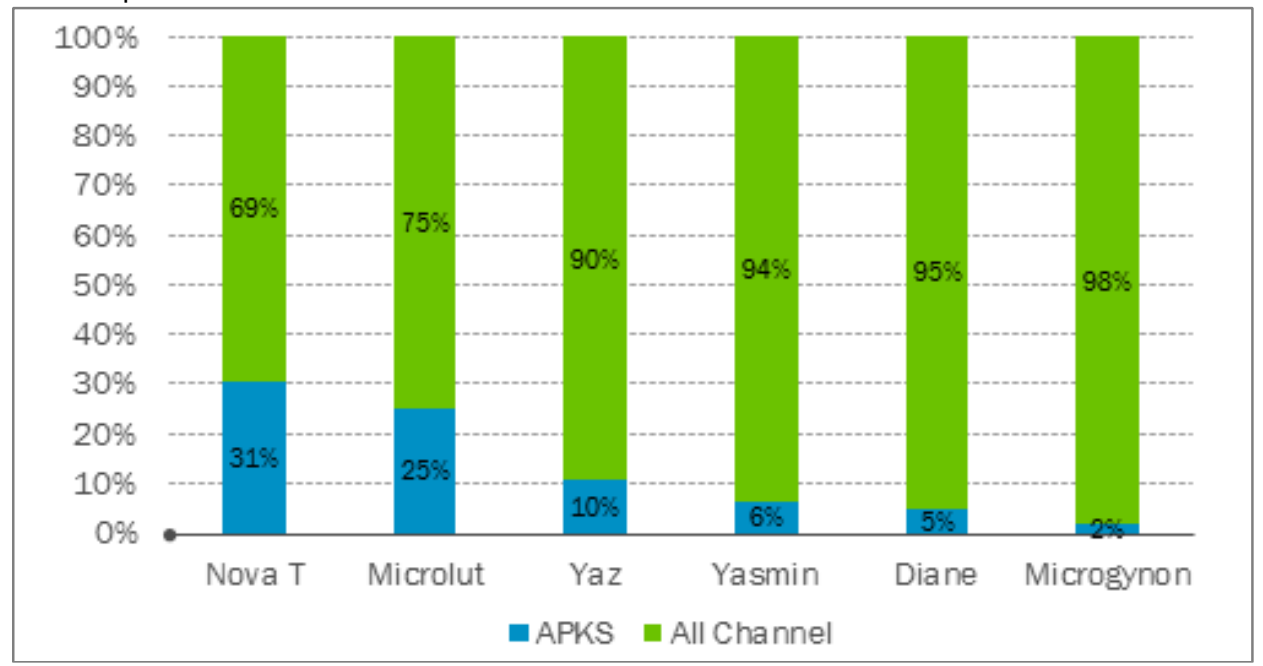

Gambar.1 Perbandingan kontribusi APKS terhadap channel lain pada tahun 2016 [4]

Dari data tersebut terbukti bahwa APKS memiliki peranan yang cukup besar terhadap penjualan beberapa produk yang diproduksi oleh bisnis pharmaceuticals PT Bayer Indonesia.

Namun, dengan jumlah APKS yang cukup banyak dan tersebar di beberapa wilayah di Indonesia, membuat departemen business channel kesulitan untuk memantau (monitoring) dan mengambil keputusan dalam hal pendistribusian dan penjualan produk-produk pada APKS. Sebagai contoh, dalam hal menganalisis hasil dari penjualan pada setiap apotek atau hasil penjualan pada setiap provinsi, dan lain sebagainya.

Oleh karena itu, dalam hal ini dibutuhkan suatu sistem informasi yang dapat memetakan data-data penjualan dari semua APKS sesuai dengan wilayah geografis dari data-data penjualan tersebut agar departemen business channel dapat mendapatkan pemahaman yang lebih baik tentang distribusi dan penjualan produk-produk melalui peta digital serta membantu pengambilan keputusan dalam hal pengembangan channel APKS, sales, dan tim pemasaran.

Peranan sistem informasi geografis terhadap Sistem Informasi APKS membuat pendistribusian produk-produk dapat berjalan dengan baik karena dengan menggunakan sistem informasi geografis maka data-data penjualan akan dipetakan berdasarkan wilayah geografisnya sehingga dapat memperkecil terjadinya kesalahan pada saat analisis pendistribusian produk. Dengan adanya sistem informasi geografis juga membuat Sistem Informasi APKS dapat memberikan bahan untuk menganalisis kebutuhan jumlah produk untuk didistribusikan ke setiap apotek kerja sama di berbagai daerah serta dapat menentukan jumlah ideal apotek kerja sama di setiap daerah melalui peta digital.

Dalam proses pengembangan Sistem Informasi APKS, metode yang digunakan adalah metode FAST (Framework for the Application of Systems Techniques). Pemilihan metode FAST dalam pengembangan Sistem Informasi APKS karena metode FAST menggunakan banyak pendekatan dalam analisis sistem yang merupakan pendekatan populer, sehingga hasil analisis yang diharapkan akan lebih tajam dan akurat [5]. FAST juga dapat dikatakan sebagai best practice dari metodologimetodologi terdahulu sebab metode FAST tidak menggunakan pendekatan tunggal pada analisis sistem. Akan tetapi metode FAST mengintegrasikan semua pendekatan populer yang diperkenalkan sebelumnya kedalam satu kumpulan agile method/metode cerdas [6].

\section{Tinjauan Pustaka}

Sistem Informasi Geografis (SIG) adalah sistem informasi yang digunakan untuk memasukkan, menyimpan, memanggil kembali, mengolah, menganalisa, dan menghasilkan data bereferensi geografis atau geospatial, untuk mendukung pengambilan keputusan dalam suatu perencanaan. Dengan menggunakan SIG maka akan lebih mudah bagi para pengambil keputusan untuk menganalisa data yang ada. Karena dengan adanya SIG maka akan digambarkan juga posisi penyebaran data pada kondisi yang sesungguhnya pada lokasi tersebut [7].

Apotek kerja sama (APKS) merupakan salah satu channel yang bekerja sama dengan PT Bayer Indonesia untuk memasarkan produk-produk yang di produksi oleh PT Bayer Indonesia terutama pada bisnis pharmaceuticals di Indonesia. Jumlah dari APKS tercatat sekitar 366 apotek yang tersebar di beberapa daerah di Indonesia, seperti Jakarta, Jawa Barat, Jawa Tengah, Yogyakarta, dan Jawa Timur. 
Sistem Informasi Apotek Kerja Sama (APKS) memiliki fungsi sebagai media untuk mengelola data penjualan (sales data) menjadi informasi penjualan yang bersifat interaktif dan informatif. Sistem Informasi APKS mampu memberikan informasi dalam berbagai bentuk seperti peta, tabel, dan diagram.

Sistem Informasi APKS memiliki fitur yang berfungsi sebagai alat monitoring dan bahan pengambilan keputusan bagi manajemen untuk mendapatkan informasi yang bersifat interaktif dan informatif, fitur-fitur tersebut diantaranya:

- Map Integration: Fitur map integration merupakan fitur yang paling utama pada Sistem Informasi APKS. Pada fitur ini, data penjualan dan data APKS akan diintegrasikan berdasarkan brand dan lokasi.

- APKS Search Tool: Fitur APKS search tool berfungsi untuk melakukan pencarian letak APKS berdasarkan nama provinsi, nama APKS, rentang nilai kontribusi APKS, dan berdasarkan penjualan dari setiap brand.

- APKS Product Analysis: Fitur APKS product analysis memiliki fungsi untuk mengelola data penjualan menjadi informasi penjualan yang berbentuk diagram yang interaktif dan informatif berdasarkan produk/brand setiap APKS.

- APKS Territory Analysis: Fitur APKS territory analysis memiliki fungsi untuk mengelola data penjualan menjadi informasi penjualan yang berbentuk tabel dan peta yang saling terintegrasi.

Sistem Informasi APKS dibangun menggunakan Google Maps Javascript API (application programming interface) yang merupakan fungsi-fungsi pemrograman yang disediakan oleh Google Maps agar Google Maps bisa di integrasikan kedalam suatu sistem informasi berbasis website. Dengan menggunakan Google Maps Javascript API, dapat memudahkan setiap developer untuk membangun suatu sistem informasi geografis. Hal tersebut dikarenakan dengan adanya Google Maps API, developer hanya perlu memanggil fungsi-fungsi yang dibutuhkan seperti menampilkan peta, menempatkan marker dan sabagainya pada peta [8].

Pada fitur Map Integration, terdapat GeoChart yang merupakan salah satu API berbentuk chart yang disediakan oleh Google. Berbeda dengan Google Maps JavaScript API, GeoChart ini bisa menampilkan data dari tingkat benua, negara, provinsi/region, hingga kota tanpa membutuhkan data dari letak bujur lintang wilayah tersebut [9].

\section{Metode Penelitian}

Pada tahap pengumpulan data, metode yang digunakan adalah metode wawancara yang merupakan suatu teknik mendapatkan informasi secara lisan dengan tujuan untuk memperoleh data yang dapat menjelaskan ataupun menjawab suatu permasalahan penelitian [10]. Dalam tahap ini, didapat berbagai macam informasi tentang kebutuhan dari departemen business channel yang harus diterapkan dalam Sistem Informasi APKS. Selain wawancara terdapat metode studi literatur untuk menghimpun data-data atau sumber-sumber seperti jurnal, buku, dokumentasi, internet, dan pustaka yang berhubungan dengan topik yang diangkat [11].

Kemudian pada tahap pengembangan sistem, metode yang digunakan adalah metode FAST. Menurut Whitten (2004) FAST dikembangkan sebagai gabungan dari praktek-praktek terbaik yang telah ditemui dalam banyak referensi komersial dan metodologi [6]. FAST adalah sebuah kerangka kerja yang cukup fleksibel untuk berbagai jenis proyek dan strategi. Yang paling penting, FAST memiliki banyak kesamaan dengan buku berbasis komersial dan metodologi yang akan ditemukan dalam praktek. Sebuah proyek dimulai dengan beberapa kombinasi dari masalah, peluang dan petunjuk dari pengguna dan diakhiri dengan sebuah solusi bisnis kerja untuk komunitas pengguna.

Pengmbangan sistem dengan metode FAST dilakukan secara berurutan yaitu meliputi tahapan Scope Definition, Problem Analysis, Requirements Analysi, Logical Design, Decision Analysis, Physical Design, Construction and Testing, dan Installation \& Delivery [6].

Metode FAST memiliki kelebihan yaitu lebih fleksibel, dapat disesuaikan dengan standar, dan dapat dikembangkan dengan metode lain yang sedang berkembang, seperti object oriented. Metode ini disebut juga metode tangkas karena kemampuannya untuk mendukung teknik lain termasuk analisis sistem yang terstruktur dan analisis berorientasi objek dan desain [6].

\section{Perancangan dan Hasil}

Berdasarkan metode FAST sebagai metode yang digunakan untuk pengembangan sistem informasi ini, terdapat delapan tahapan [6] yang dilakukan diantaranya:

A. Scope Definition (Definisi Lingkup)

Terdapat beberapa lingkup/batasan dalam pengembangan sistem informasi ini, diantaranya:

- $\quad$ Sistem informasi ini berbasis website dengan teknologi ASP.NET.

- Sistem informasi ini menyajikan informasi berbasis peta, tabel, dan diagram sebagai bahan pengambilan keputusan.

- $\quad$ Sistem informasi ini akan terintegrasi dengan data-data yang telah ada di PT Bayer Indonesia, seperti data karyawan, data daerah, dan data aplikasi.

- $\quad$ Sistem informasi ini digunakan oleh departemen business channel dan sales yang berada di kantor pusat PT Bayer Indonesia, bukan karyawan yang berada di daerah-daerah/lapangan. 
- Data penjualan yang berbentuk data mentah (raw data) diperoleh dari departemen sales. Data mentah tersebut akan dimasukan kedalam Sistem Informasi APKS oleh departemen sales.

B. Problem Analysis (Analisis Permasalahan)

Pada analisis permasalahan terdapat beberapa masalah untuk diimplementasikan pada Sistem Informasi APKS, diantaranya adalah:

- Bagaimana cara untuk membuat sistem informasi geografis yang dapat memetakan data-data penjualan di setiap apotek sesuai dengan wilayahnya dengan menggunakan peta digital.

- Bagaimana cara untuk membuat sistem informasi yang dapat membantu dalam pengambilan keputusan dalam hal pengembangan channel APKS, sales, dan tim pemasaran.

C. Requirements Analysis (Analisis Kebutuhan)

Pada tahap analisis kebutuhan ini, dilakukan beberapa metode untuk pengumpulan data diantaranya adalah:

1) Wawancara: Pada tahapan wawancara, didapat beberapa data yang dapat dimanfaatkan dari departemen business channel dan sales, data tersebut diantaranya adalah data sales dan data daftar APKS.

2) Studi Literatur: Pada tahapan ini, didapat beberapa informasi mengenai teknologi yang dapat digunakan untuk membangun Sistem Informasi APKS, seperti Google Maps API dan GeoChart.

D. Logical Design (Desain Logis)

Pada tahap logical design, dilakukan analisis terhadap alur proses data dari awal hingga menjadi informasi yang berbentuk peta, tabel, dan diagram. Berikut merupakan gambar dari business process pada Sistem Informasi APKS:

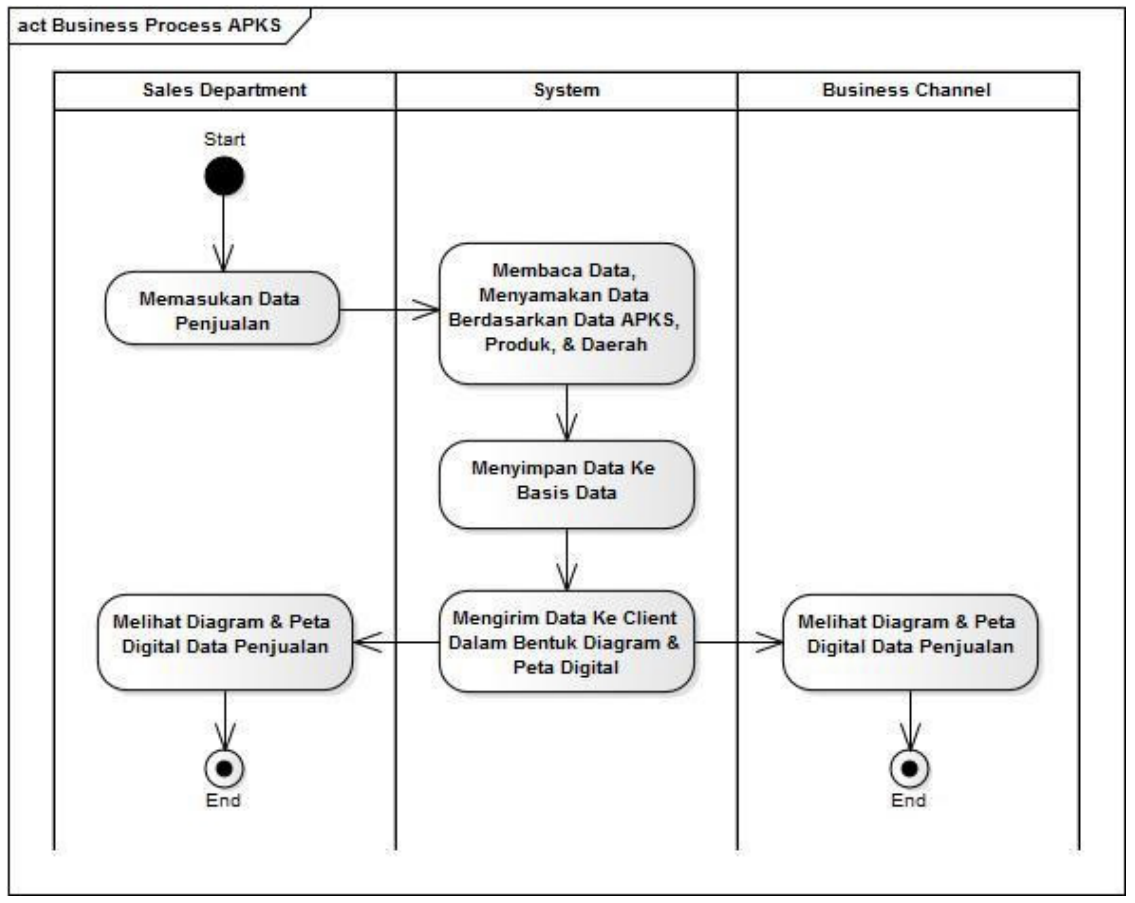

Gambar.2 Business Process Sistem Informasi APKS

Proses dimulai dari departemen sales yang akan mengupload data penjualan ke Sistem Informasi APKS, kemudian sistem akan membaca dan menyamakan data APKS, produk, dan daerah yang ada pada data penjualan dengan data yang ada pada Sistem Informasi APKS. Selanjutnya data akan disimpan ke dalam basis data dan dikirim kepada client (browser) dalam bentuk peta, tabel, dan diagram.

Pada tahap ini juga dilakukan analisis use case untuk mengetahui peranan aktor pada Sistem Informasi APKS, berikut merupakan diagram use case pada Sistem Informasi APKS: 


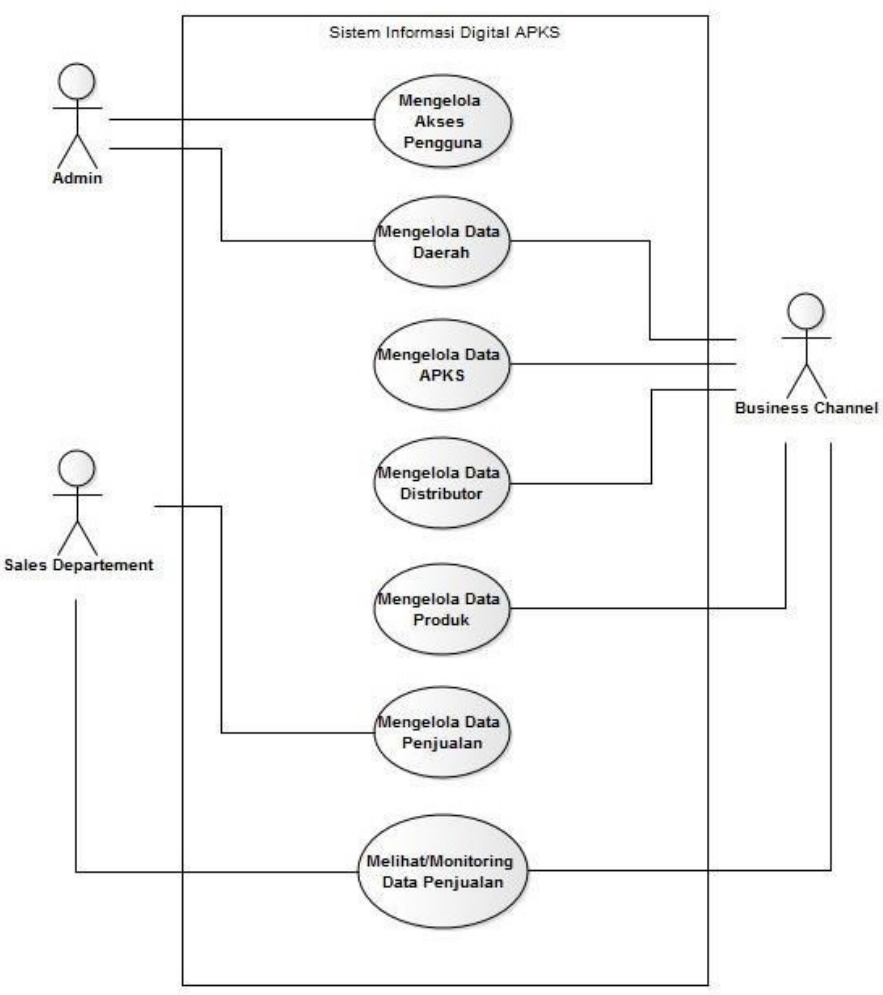

Gambar.3 Use Case Sistem Informasi APKS

Pada diagram use case tersebut terdapat beberapa aktor yang memiliki peranannya masing-masing dalam sistem informasi ini. Aktor-aktor tersebut diantaranya adalah Admin, Sales Departement, dan Business Channel. Ketiga aktor tersebut saling menjalankan penanannya untuk mencapai tujuan yang sama.

Admin memiliki peran yaitu mengelola data akses bagi pengguna untuk mengakses sistem informasi ini, serta mengelola data daerah yang akan digunakan sebagai data master pada sistem informasi ini.

Business channel memiliki beberapa peran diantaranya adalah mengelola data daerah, data APKS, data distributor, dan data produk yang digunakan sebagai data master pada sistem informasi ini. Fungsi data-data master adalah sebagai data identitas yang akan digunakan sebagai bahan transaksi data pada sistem informasi ini.

Departemen sales memiliki peran untuk mengelola data penjualan. Data penjualan ini merupakan data mentah yang dikumpulkan dari sales di lapangan. Kemudian data tersebut disatukan oleh departemen sales dan dimasukan dalam sistem informasi ini untuk dikelola menjadi bahan pengambil keputusan dan bahan analisis.

Kemudian terdapat fitur untuk monitoring data penjualan yang dapat diakses oleh departemen sales dan departemen business channel.

E. Decision Analysis (Analisis Keputusan)

Pada tahapan decision analysis, didapat beberapa keputusan dalam hal pengembangan Sistem Informasi APKS, diantaranya adalah:

- Sistem Informasi APKS memiliki 4 halaman untuk manajemen master data diantaranya Halaman Sales, Halaman APKS, Halaman Brand \& Product, dan Halaman Channel Amount.

- Sistem Informasi APKS memiliki 4 halaman untuk manajemen report data diantaranya Halaman Map Integration, Halaman Search Tool, Halaman Product Analysis, dan Halaman Territory Analysis.

- Sistem Informasi APKS akan mengelola data penjualan menjadi informasi berbentuk peta, tabel, dan diagram untuk menampilkan informasi Year-to-date (YTD), Average (AVG), Growth (Gr), dan Final Year (FY) berdasarkan dua tahun sebelumnya hingga tahun saat ini.

- Setiap peta pada Halaman Map Integration akan memberikan informasi tentang APKS dan hasil analisis data penjualannya.

- Pencarian APKS pada Halaman search tool dapat dilakukan berdasarkan tiga kategori diantaranya berdasarkan area, berdasarkan nilai kontribusi, dan berdasarkan penjualan brand. 
- Setiap informasi pada Halaman Territory Analysis akan terintegrasi dengan peta untuk melihat lokasi setiap APKS dalam peta.

- Pada Halaman Product Analysis akan menampilkan informasi penjualan setiap brand berdasarkan tahun penjualannya.

F. Physical Design

Pada tahapan physical design ini, didapat beberapa kebutuhan untuk pengembangan Sistem Informasi APKS dari sisi physical, diantaranya sebagai berikut:

TABEL. 1 KeBUtuHAN PHYSICAL ENVIRONMENT DALAM PENGEMBANGAN SISTEM INFORMASI APKS

\begin{tabular}{|c|c|c|}
\hline No & Requirement & Description \\
\hline 1 & Hardware requirements & $\begin{array}{l}\text { Untuk menjalankan Sistem Informasi APKS dibutuhkan } \\
\text { hardware dengan minimal kapasitas: } \\
\text { Client: } \\
\begin{aligned}- & 512 \mathrm{MB} \text { of RAM } \\
- & 1 \mathrm{GHz} \text { of Processor } \\
- & \text { Any machine that can access a webpage } \\
\text { Server: } & \\
- & 2 \mathrm{~GB} \text { of RAM } \\
- & 2 \mathrm{GHz} \text { of Processor } \\
- & \text { Hard Disk } 200 \mathrm{~GB}\end{aligned}\end{array}$ \\
\hline 2 & Architecture & $\begin{array}{l}\text { Dibutuhkan beberapa server yang berbeda berdasarkan } \\
\text { tujuan dari pengembangan sistem, sebagai berikut: } \\
\begin{aligned}- & \text { Productive } \\
- & \text { Development } \\
- & \text { Test and/or Training }\end{aligned}\end{array}$ \\
\hline 3 & Software requirements & $\begin{array}{ll}\text { Untuk menjalankan Sistem Informasi APKS dibutuhkan } \\
\text { software dengan minimal kapasitas: } \\
\text { Client: } \\
-\quad \text { Internet Explorer / Mozilla Firefox } \\
-\quad \text { Microsoft .NET Framework Version } 3.0 \\
-\quad \text { Windows XP/Vista/7/8/10 } \\
\text { Server: } & \\
- & \text { Windows Server } 2008 \\
- & \text { SQL Server } 2008 \text { R2 } \\
- & \text { Internet Information Services (IIS) } \\
- & \text { Microsoft .NET Framework Version } 3.0\end{array}$ \\
\hline 4 & Network requirements & Menggunakan koneksi internet dan koneksi VPN \\
\hline
\end{tabular}

G. Construction

Berdasarkan hasil analisis yang telah dilakukan sebelumnya, maka telah didapatkan hasil dari pembangunan Sistem Informasi APKS yang telah diuji dan siap digunakan oleh pengguna, berikut merupakan hasil dari pengembangan Sistem Informasi APKS:

\section{- Halaman Sales Data}

\begin{tabular}{|c|c|c|c|c|c|c|c|c|c|c|c|}
\hline \multicolumn{12}{|c|}{ SALES DATA } \\
\hline \multirow{2}{*}{\multicolumn{3}{|c|}{$\begin{array}{l}\text { Download Sample Sales Data } \\
\text { Upload Sales Data }\end{array}$}} & : & \multicolumn{3}{|c|}{ Download Sample } & & & & & \\
\hline & & & : & \multicolumn{2}{|l|}{ No Data } & Browse... & & & & & \\
\hline & & SBE Team & \multicolumn{2}{|r|}{ Brand } & Product & QTY & Amount & APKS & Channel & Month & Year \\
\hline & & & & 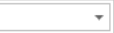 & & 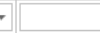 & & & & & \\
\hline Edit & Delete & WH & Nova & & NOVA T-380 1X1 ID & 1 & $205,320.00$ & EYCKMAN, APT & Pharmacy & 1 & 2015 \\
\hline Edit & Delete & WH & Microg & ynon & $\begin{array}{l}\text { MICROGYNON } 25 \times 28 \\
\text { SCT BSP }\end{array}$ & 1 & $261,360.00$ & EYCKMAN, APT & Pharmacy & 1 & 2015 \\
\hline Edit & Delete & WH & Yasmir & & YASMIN $1 \times 21 \mathrm{SCT}$ & 2 & $312,720.00$ & EYCKMAN, APT & Pharmacy & 1 & 2015 \\
\hline Edit & Delete & WH & Nova & & NOVA T-380 1 X1 ID & 7 & $1,437,240.00$ & RAMLAH PARIIB, APT & Pharmacy & 1 & 2015 \\
\hline Edit & Delete & WH & Diane & & DIANE 35 SCT BSP & 10 & $848,000.00$ & UUN FARMA, APT & Pharmacy & 1 & 2015 \\
\hline
\end{tabular}

Gambar.4 Halaman Sales Data 
Pada Halaman Sales, terdapat tombol download sample yang berisi format kolom untuk mengupload data sales dalam bentuk file excel. Pada halaman ini, pihak dari departemen sales hanya perlu untuk mengklik tombol browse untuk memilih data penjualan lalu menekan tombol save untuk menyimpan data pada Sistem Informasi APKS.

- Halaman Master Data

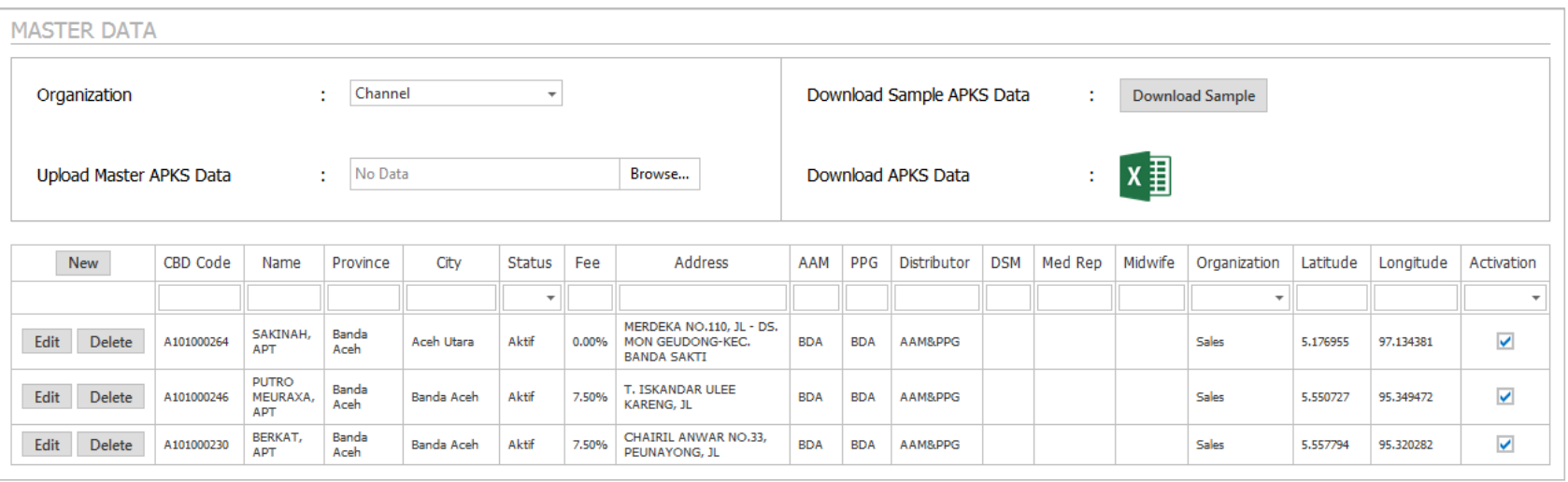

Gambar.5 Halaman APKS Master Data

Pada Halaman Master Data, terdapat tombol download sample yang berisi format kolom untuk mengupload data sales dalam bentuk file excel serta ikon file excel yang digunakan untuk mendownload data yang telah tersimpan pada Sistem Informasi APKS. Pada halaman ini, pihak dari departemen business channel hanya perlu memilih field organization untuk menentukan asal data APKS dan mengklik tombol browse untuk memilih data APKS lalu menekan tombol save untuk menyimpan data pada Sistem Informasi APKS.

Pada halaman ini juga pihak business channel dapat memilih untuk memasukan data APKS secara langsung tanpa menggunakan file excel/upload yaitu dengan cara mengklik tombol new yang terdapat pada bagian header tabel, lalu menekan tombol save untuk menyimpan data.

- Halaman Brand \& Product

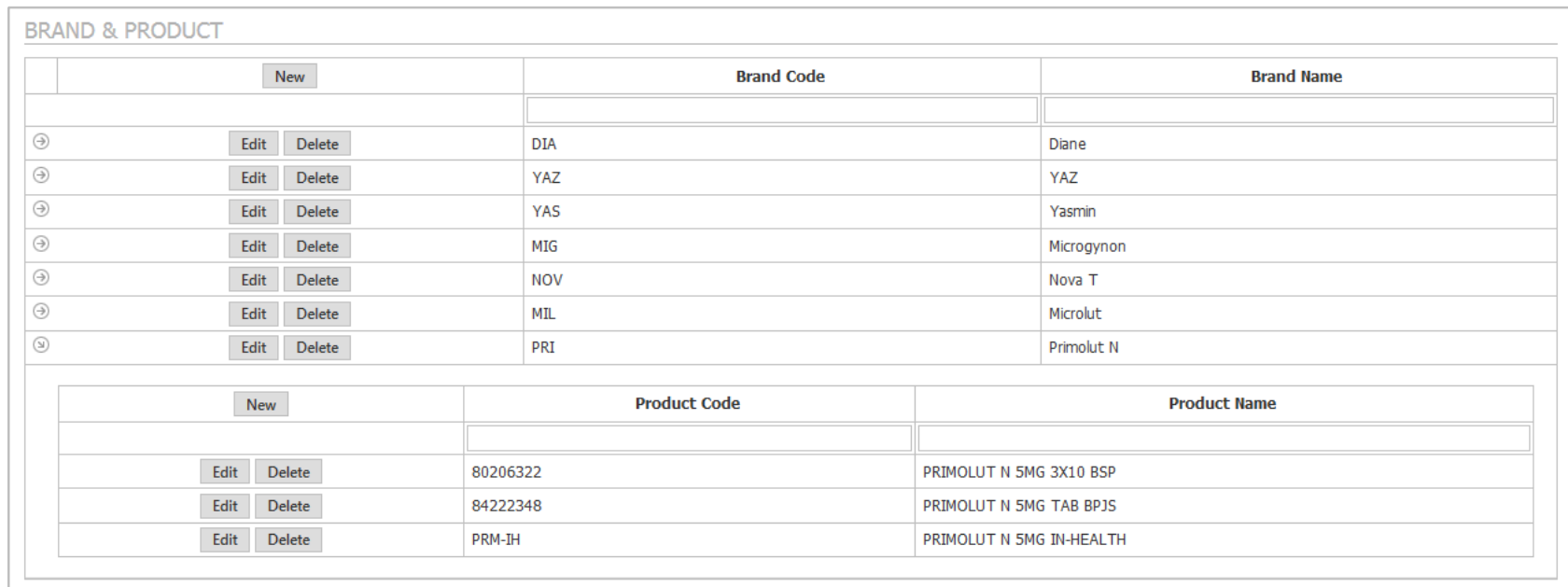

Gambar.6 Halaman Brand \& Product

Pada Halaman Brand \& Product pihak business channel dapat memasukan data brand dengan cara mengklik tombol new yang terdapat pada bagian header tabel brand/tabel utama, lalu menekan tombol save untuk menyimpan data. Kemudian untuk memasukan data product dengan cara mengklik tombol new yang terdapat pada bagian header tabel produk sesuai dengan brandnya masing-masig, lalu menekan tombol save untuk menyimpan data. 
- Halaman Channel Amount

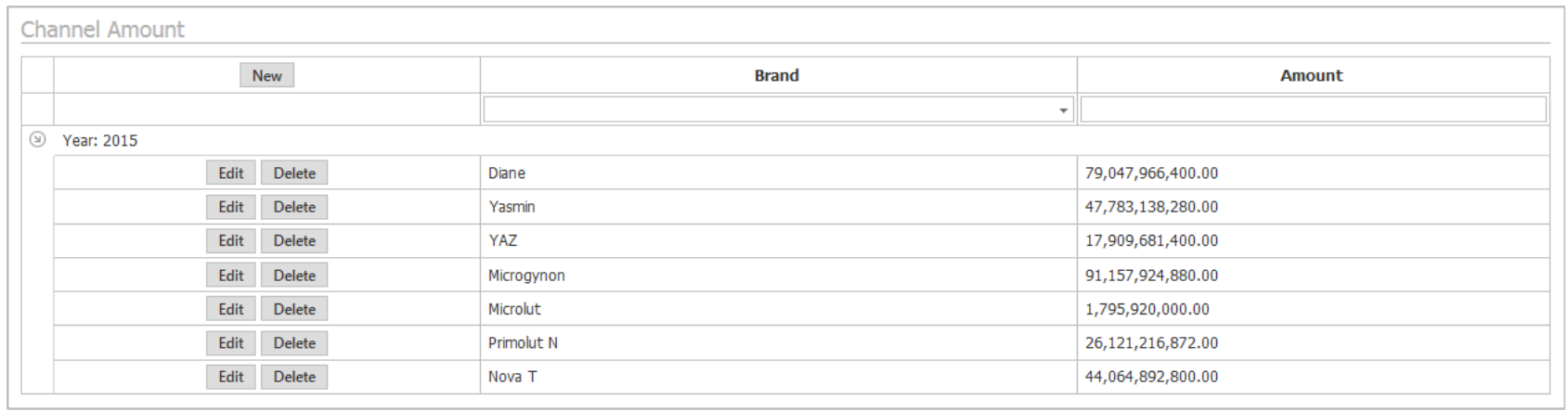

Gambar.7 Halaman Channel Amount

Pada Halaman Channel Amount pihak business channel dapat memasukan data amount dari total penjualan semua channel termasuk APKS dengan cara mengklik tombol new yang terdapat pada pada bagian header tabel, lalu menekan tombol save untuk menyimpan data.

Dari data amount yang di input tersebut, maka akan diperoleh nilai APKS, dimana nilai APKS tersebut memiliki persamaan seperti berikut:

$$
\text { NilaiAPKS }(\%)=(\text { BrandAmoun } t-\text { TotalBrand AmoutAPKS }) * 100
$$

Persamaan (1) merupakan persamaan untuk menghitung nilai APKS dalam persentase. Pada (1) tersebut terdapat nilai dari Total Brand Amount APKS yang diperoleh dari hasil perhitungan data per brand dari semua APKS yang telah di input pada basis data, tepatnya pada penginputan data sales di Halaman Sales Data.

Kemudian, (1) akan digunakan untuk analisis perbandingan kontribusi penjualan APKS jika dibandingkan dengan channel yang lain. Hasil dari (1) akan ditampilkan pada Halaman Product Analysis dalam bentuk diagram sebagai hasil dari analisis penjualan produk setiap tahunnya.

- Halaman Search Tool

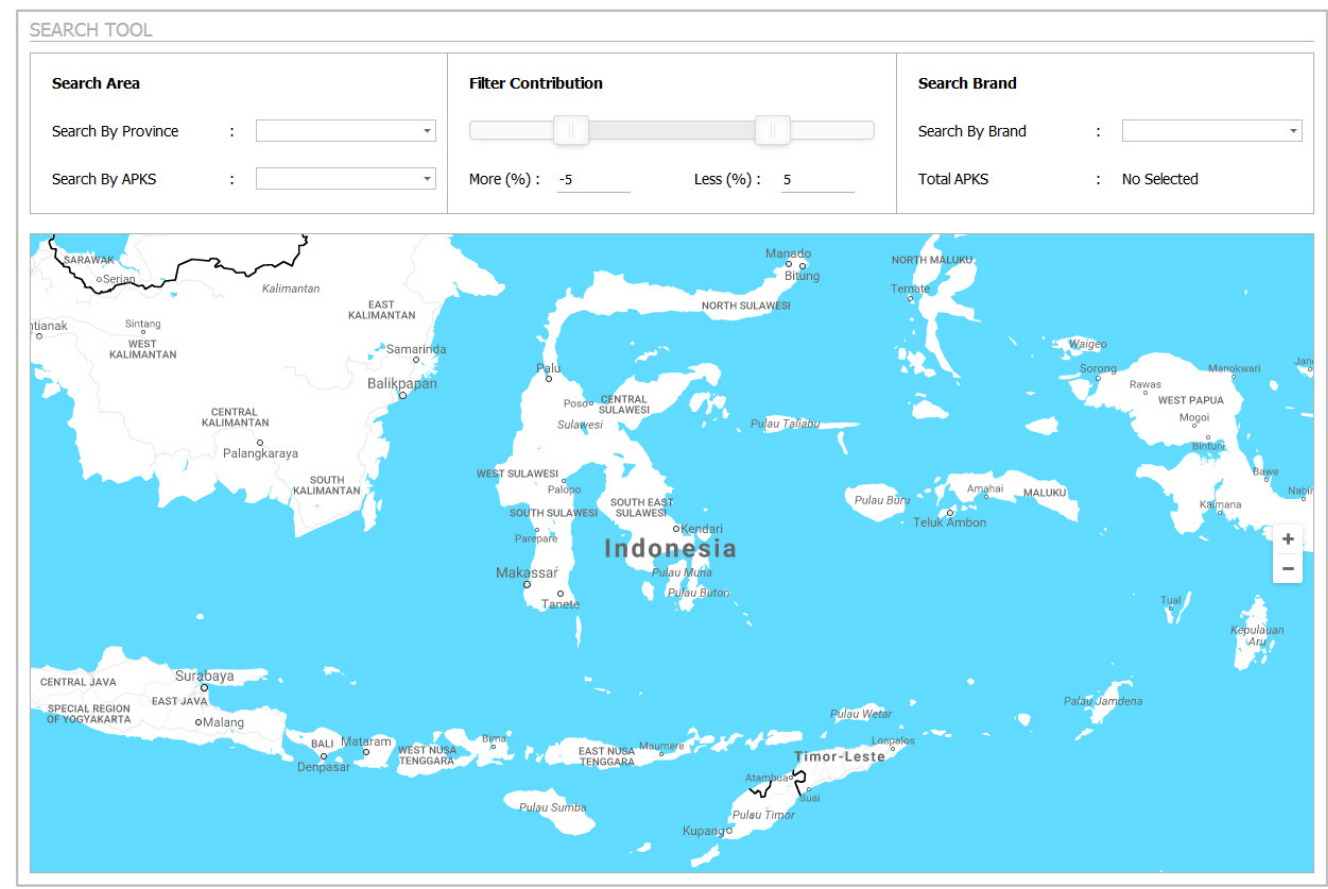

Gambar.8 Halaman Search Tool 
Pada Halaman Search Tool terdapat tiga kategori untuk melakukan pencarian, yaitu dengan berdasarkan nama provinsi dan nama APKS, berdasarkan rentang nilai kontribusi APKS, dan berdasarkan penjualan dari setiap brand. Untuk melakukan pencarian, pengguna hanya perlu untuk memilih kata kunci di setiap kategori agar peta menampilkan APKS berdasarkan kata kunci yang dipilih.

\section{- Halaman Map Integration}

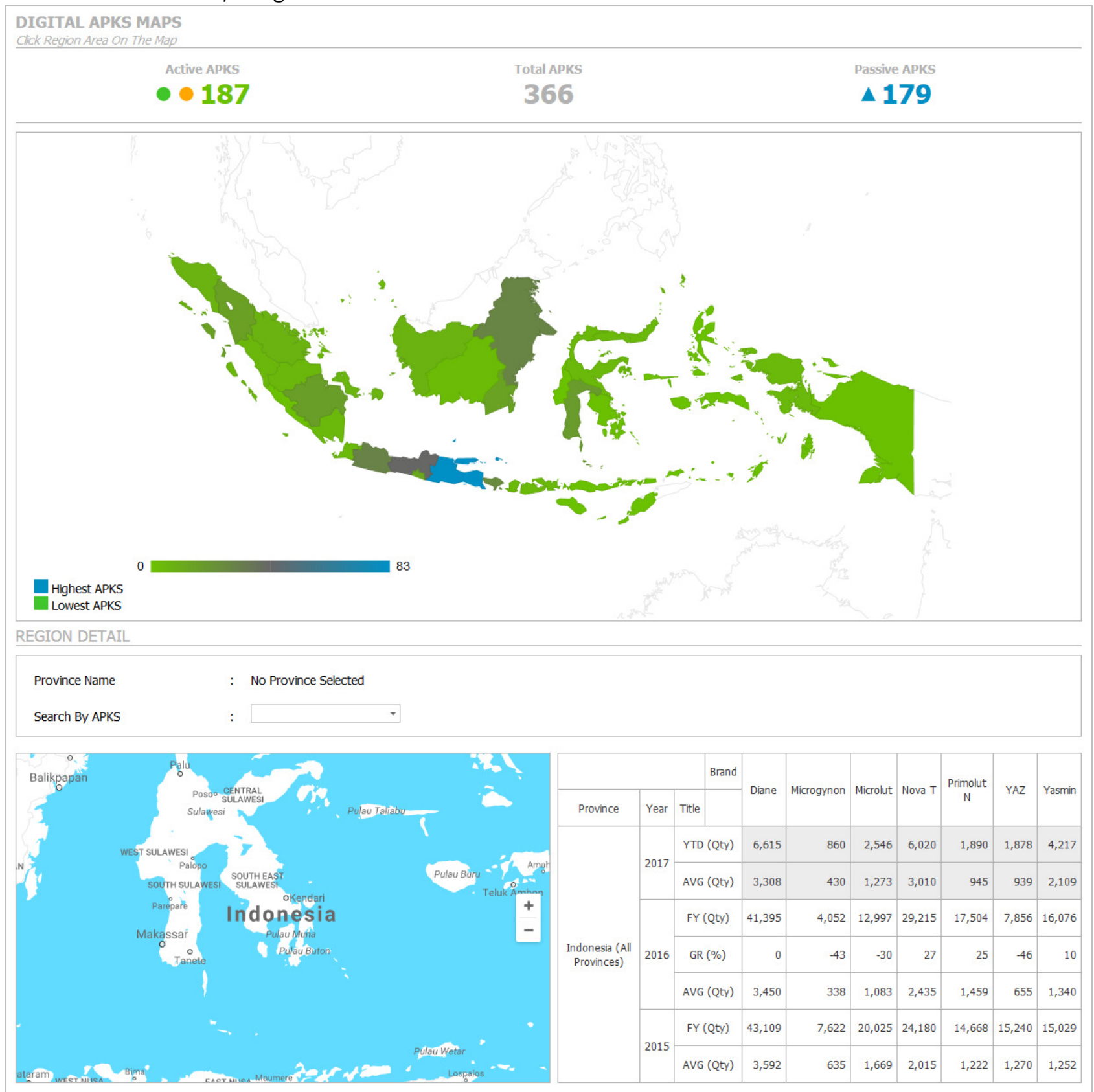

Gambar.9 Halaman Map Integration

Pada Halaman Map Integration terdapat peta utama yang berfungsi untuk menampilkan informasi dari total keseluruhan APKS dan total APKS yang aktif pada setiap provinsi di Indonesia. Pada saat mengklik setiap provinsi pada peta tersebut maka detail informasi akan muncul di bagian region detail. Informasi yang akan disediakan adalah perhitungan Year-to-date (YTD), Average (AVG), Growth (Gr), dan Final Year (FY) berdasarkan 
dua tahun sebelumnya hingga tahun saat ini serta terdapat peta untuk menandakan letak setiap APKS pada provinsi yang diklik.

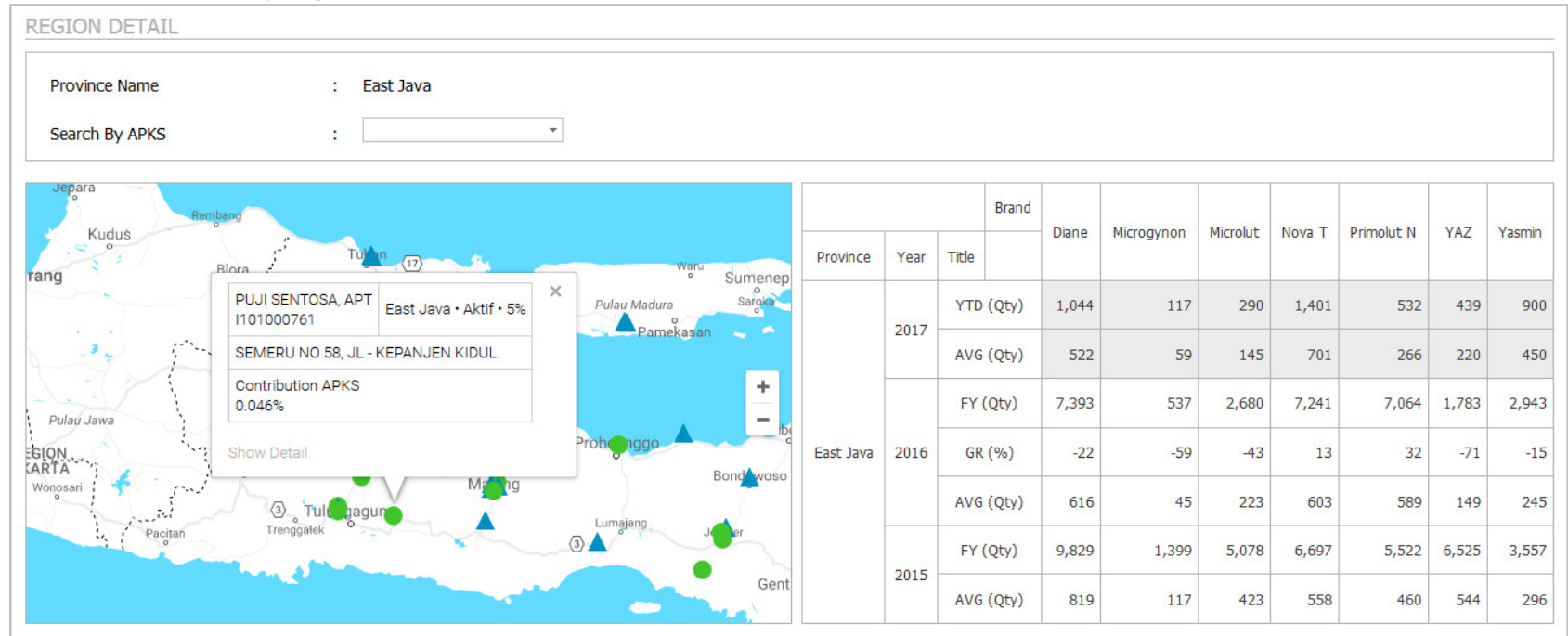

Gambar.10 Halaman Map Integration Region Detail

- Halaman Product Analysis

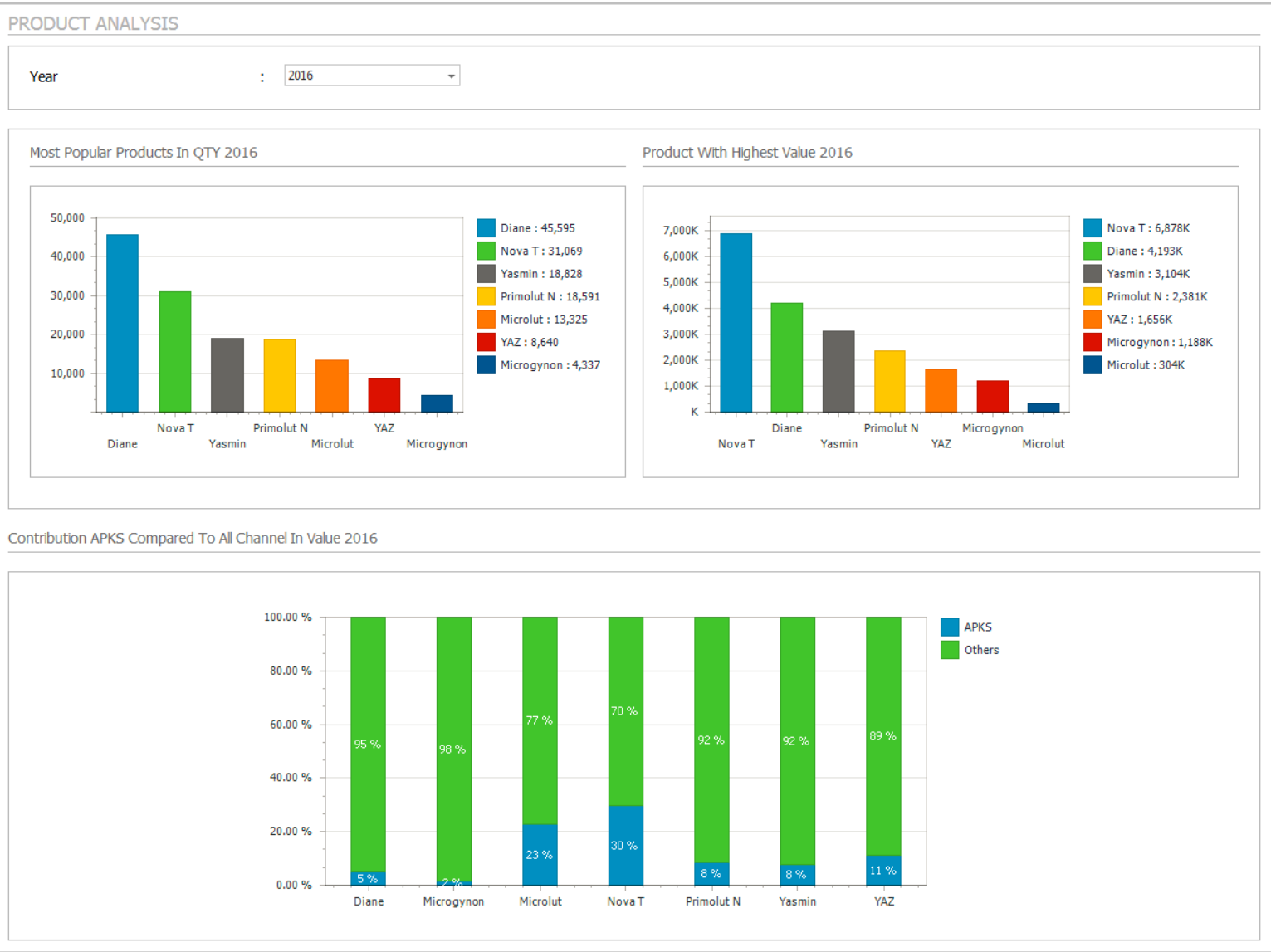

Gambar.11 Halaman Product Analysis 
- Halaman Territory Analysis

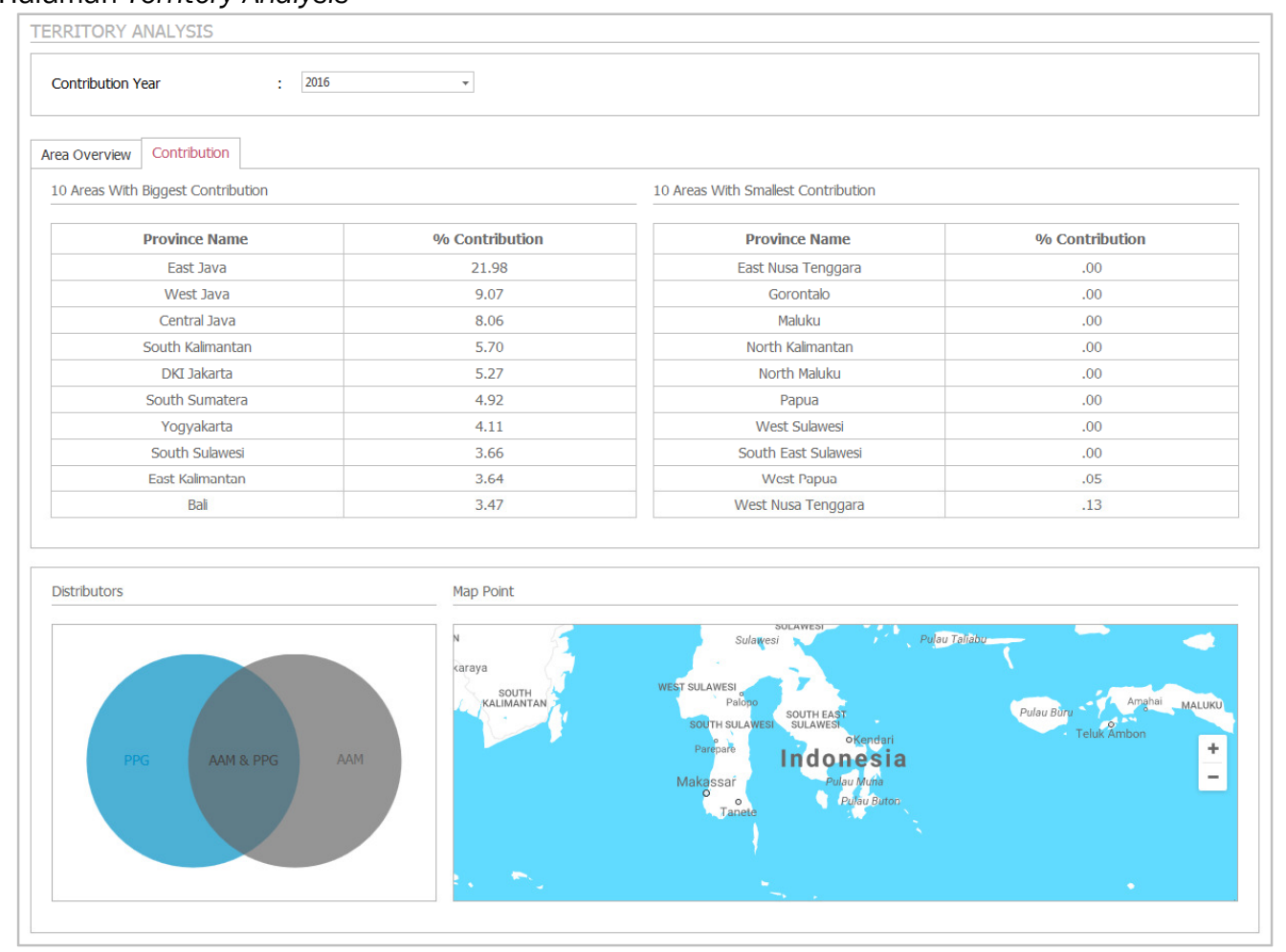

Gambar.12 Halaman Territory Analysis

Pada Halaman Product Analysis dan Tarritory Analysis akan menampilkan informasi dalam bentuk diagram dan tabel ketika tahun yang berdasarkan data penjualannya dipilih. Pada Halaman Tarritory Analysis terdapat peta yang memiliki fungsi untuk menampilkan semua APKS ketika provinsi yang terdapat pada tabel diklik.

\section{H. Installation \& Delivery}

Pada tahapan terakhir ini, Sistem Informasi APKS dideploy ke server productive agar bisa diakses dilingkungan PT Bayer Indonesia dengan cara melakukan koneksi ke jaringan internet dan ke jaringan VPN PT Bayer Indonesia.

\section{KESIMPULAN}

Berdasarkan pembahasan tentang Sistem Informasi APKS, maka didapat beberapa kesimpulan, diantaranya:

- Sistem Informasi Apotek Kerja Sama (APKS) memiliki fungsi sebagai media untuk mengelola data penjualan (sales data) menjadi informasi penjualan yang bersifat interaktif dan informatif. Sistem Informasi APKS mampu memberikan informasi dalam berbagai bentuk seperti peta, tabel, dan diagram.

- Business process Sistem Informasi APKS dimulai dari departemen sales yang mengupload data penjualan ke Sistem Informasi APKS, kemudian sistem akan membaca dan menyamakan data APKS, produk, dan daerah yang ada pada data penjualan dengan data yang ada pada Sistem Informasi APKS. Selanjutnya data akan disimpan ke dalam basis data dan dikirim kepada client (browser) dalam bentuk peta, tabel, dan diagram.

- Sistem Informasi APKS membantu departemen business channel agar mendapatkan pemahaman yang lebih baik tentang distribusi dan penjualan produk-produk melalui peta digital serta membantu pengambilan keputusan dalam hal pengembangan channel APKS, sales, dan tim pemasaran.

\section{UCAPAN TERIMA KASIH}

Penulis mengucapkan terima kasih kepada Departemen Teknologi Informasi PT Bayer Indonesia dan Departemen Business Channel PT Bayer Indonesia yang telah membantu proses pembuatan penelitian ini. 


\section{REFERENSI}

[1] Tentang Bayer Indonesia. [Online]. Available:http://www.bayer.co.id/id/tentang-bayer/bayer-indonesia/profil-organisasi-perusahaan/

[2] Nama, Fakta, Figur Tentang Bayer. [Online]. Available:http://www.bayer.co.id/id/tentang-bayer/bayer-global/profil-organisasi-/

[3] Pharmaceuticals Bayer. [Online]. Available:http://www.bayer.co.id/id/tentang-bayer/bayer-global/profil-organisasi-/pharmaceuticals/

[4] Laporan Analisis Data APKS: Departement Business Channel PT Bayer Indonesia, 2016

[5] Bardidi, Ali, Firdaus, Afryan, dan Firdaus. 2010. 'Pengembangan Sistem Informasi Manajemen Perkuliahan Pada Fakultas IImu Komputer Universitas Sriwijaya'. Jurnal Sistem Informasi, vol. 2, no. 1, hh. 169-178.

[6] Whitten, Jeffery L., Bentley, Lonnie D., dan Dittman Kevin C. Metode Desain dan Analisis Sistem. Indianapolis:Penerbit ANDI, 2004

[7] Harahap, S. A. dan Yanuarsyah, I. 2012. 'Aplikasi Sistem Informasi Geografis (SIG) Uuntuk Zonasi Jalur Penangkapan Ikan Di Perairan Kalimantan Barat'. Jurnal Akuatika, vol. 3, no. 1, hh. 40-48.

[8] Documentation Web Maps JavaScript API. [Online]. Available:https://developers.google.com/maps/documentation/javascript/

[9] Documentation Visualization: GeoChart. [Online]. Available:https://developers.google.com/chart/interactive/docs/gallery/geochart\#full

[10] Hasibuan, Zainal A. Metodologi Penelitian Pada Bidang IImu Komputer Dan Teknologi Informasi. Depok:Fakultas IImu Komputer Universitas Indonesia, 2007

[11] Setiawan, Tomi dan Yulian, Bayu Eka. 2016. 'Negara dan Peran Ilmu Lingkungan dalam Menunjang Pembangunan Berkelanjutan'. Prosiding Seminar Nasional MIPA 2016:Peran Penelitian IImu Dasar dalam Menunjang Pembangunan Berkelanjutan, Jatinangor, 27-28 Oktober 2016 